\title{
Diagnosis and Management of Functional Chest Pain in the Rome IV Era
}

\author{
Ronnie Fass, ${ }^{1 *}$ Fahmi Shibli, ${ }^{1}$ and Jose Tawil ${ }^{2}$ \\ ${ }^{I}$ The Esophageal and Swallowing Center, MetroHealth Medical Center and Case Western Reserve University, Cleveland, OH, USA; and \\ ${ }^{2}$ Departamento de Trastornos Funcionales Digestivos, Gedyt-Gastroenterología Diagnóstica y Terapéutica, BuenosAires, Argentina
}

Functional chest pain accounts for about a third of the patients with noncardiac chest pain. It is a very common functional esophageal disorder that remains even today a management challenge to the practicing physician. Based on the definition offered by the Rome IV criteria, diagnosis of functional chest pain requires a negative workup of noncardiac chest pain patients that includes, proton pump inhibitor test or empirical proton pump inhibitor trial, endoscopy with esophageal mucosal biopsies, reflux testing, and esophageal manometry. The mainstay of treatment are neuromodulators that are primarily composed of anti-depressants. Alternative medicine and psychological interventions may be provided alone or in combination with other therapeutic modalities.

(J Neurogastroenterol Motil 2019;25:487-498)

\section{Key Words}

Alternative medicine; Chest pain; Endoscopy; Neuromodulators; Proton pump inhibitors

\section{Introduction}

Functional gastrointestinal disorders (FGIDs) are disorders of gut-brain interaction, defined as gastrointestinal symptoms that are related to any combination of motility disturbance, visceral hypersensitivity, altered mucosal and immune function, altered gut microbiota, and altered central nervous system processing. ${ }^{1}$ In addition, functional esophageal disorders are defined by chronic esophageal symptoms in the absence of identifiable structural, inflammatory, motor, or metabolic mechanism as the etiology. ${ }^{2}$ Unlike other FGIDs, esophageal motor abnormalities, except ineffective esophageal motility and fragmented peristalsis, are not considered part of the multi-faceted presentation of a functional esophageal disorder. Rome IV criteria identified 5 functional esophageal disorders, including functional chest pain (FCP), functional heartburn, reflux hypersensitivity, globus, and functional dysphagia. Diagnosis of all functional esophageal disorders requires the exclusion of gastroesophageal reflux disease (GERD), eosinophilic esophagitis, and a major esophageal motor disorder (vide infra).

FCP accounts for more than a third of the patients diagnosed with esophageal related noncardiac chest pain (NCCP). Other underlying mechanisms of esophageal related NCCP include GERD, esophageal dysmotility, psychological comorbidity, and less commonly eosinophilic esophagitis. After GERD, FCP is the second most common cause of NCCP. The pathophysiology of FCP is poorly understood, but most patients demonstrate increased mechano- or chemo-receptor sensitivity to esophageal distention or acid perfusion, respectively. This suggests the presence of esophageal hypersensitivity, which is defined as the perception of

Received: August 1, 2019 Revised: None Accepted: August 7, 2019

↔ This is an Open Access article distributed under the terms of the Creative Commons Attribution Non-Commercial License (http://creativecommons. org/licenses/by-nc/4.0) which permits unrestricted non-commercial use, distribution, and reproduction in any medium, provided the original work is properly cited.

${ }^{*}$ Correspondence: Ronnie Fass, MD, FACG

The Esophageal and Swallowing Center, Digestive Health Center, MetroHealth Medical Center, Division of Gastroenterology and Hepatology, 2500 MetroHealth Drive, Cleveland, OH 44109, USA

Tel: +1-216-778-3145, Fax: +1-216-778-2074,E-mail: ronnie.fass@gmail.com 
non-painful esophageal stimuli as being painful and painful stimuli as being more painful. ${ }^{3-5}$ Central and to a lesser extent peripheral sensitization have been proposed as the underlying mechanisms of esophageal hypersensitivity. Other mechanisms responsible for the development of FCP include, altered central processing of intra-esophageal stimuli, hypervigilance, autonomic dysregulation, abnormal mechano-physical properties of the esophagus, and psychological comorbidity (panic disorder, anxiety, somatization, and depression) (Table 1).

\section{Definition}

FCP is one of the underlying mechanisms of NCCP. NCCP is defined as recurrent chest pain that is indistinguishable from ischemic heart pain after a reasonable workup has excluded a cardiac cause. ${ }^{6}$

FCP is defined as retrosternal chest pain or discomfort, absence of associated esophageal symptoms such as heartburn and dysphagia, absence of evidence that GERD, eosinophilic esophagitis, and major esophageal motor disorder (achalasia, jackhammer esophagus, distal esophageal spasm, absent contractility, and esophagogastric junction outflow obstruction) are present. Prior diagnosis of FCP, cardiac cause should be first ruled out. Importantly, the definition of FCP requires that all other organic or functional esophageal causes have been excluded.

Criteria must be fulfilled for the past 3 months with symptom onset at least 6 months before diagnosis with frequency of at least once a week. Symptom frequency was determined based on findings of a normative survey designed by Rome IV among 1162 subjects without known gastroesophageal disorders who are representative of the United States adult population. ${ }^{7}$

The Rome IV definition of FCP differs from the definition of Rome III, by the exclusion of eosinophilic esophagitis, major esophageal motor disorders, and cardiac cause. ${ }^{8}$ In addition, Rome III used the term FCP of presumed esophageal origin, which was shortened by Rome IV to FCP.

Table 1. Underlying Mechanisms of Functional Chest Pain

- Esophageal hypersensitivity

- Peripheral and/or central sensitization

- Altered central processing of esophageal stimuli

- Autonomic dysregulation

- Abnormal mechanophysical properties of the esophagus

- Psychological comorbidity

- Hypervigilance
There are less than a handful of studies that have assessed the prevalence of FCP. Population-based studies reported that the prevalence of NCCP ranges between 19.0-33.0\% in the general adult population. ${ }^{9,10}$ However, those prevalence rates include various esophageal disorders associated with chest pain such as GERD, eosinophilic esophagitis, esophageal motor disorders, and FCP. Fass and Dickman ${ }^{11}$ have estimated that within the NCCP cohort, 50.0-60.0\% have GERD, 15.0-18.0\% esophageal dysmotility, and approximately 32.0-35.0\% FCP. In a study that included 177 patients with NCCP, who were referred for esophageal motility testing and $\mathrm{pH}$ monitoring, Gomez et $\mathrm{al}^{12}$ demonstrated esophageal motility disorders in $31.0 \%$ of the patients, abnormal esophageal acid exposure in $35.0 \%$ of the patients, and FCP in $33.0 \%$ of the patients. Overall, it appears that FCP accounts for at least a third of the patients presenting with NCCP.

\section{Diagnosis}

Diagnosis of FCP requires the exclusion of non-esophageal and esophageal causes of chest pain. An initial evaluation of patients with chest pain should include a cardiac workup, ${ }^{13}$ which the extent of it should be decided by a cardiologist. This recommendation is driven by the recognition that the morbidity and mortality of coronary artery disease far exceeds that of esophageal related causes of chest pain.

Medical history, pain characteristics, associated symptoms, and physical examination should help to exclude non-esophageal etiology for chest pain, such as pulmonary, pleural, pericardial, musculoskeletal, neurological, biliary, pancreatic, and psychiatric disorders. ${ }^{13}$

Thereafter, a diagnostic workup will discern the various esophageal causes for NCCP, including GERD, major esophageal motor disorders, eosinophilic esophagitis, and $\mathrm{FCP}^{14}$ All patients should be evaluated for psychological comorbidity, preferably by a psychiatrist or psychologist with expertise in the area of FGIDs. It should be emphasized that NCCP could be one of the presenting symptoms of panic disorder, which accounts for up to $41.0 \%$ of the emergency department visits for chest pain that is not due to cardiac cause. $^{15,16}$

The workup for NCCP-related esophageal disorders include, proton pump inhibitor (PPI) trial, endoscopy with esophageal biopsies, reflux testing, and high-resolution esophageal manometry (Table 2). ${ }^{17}$ If all of the aforementioned tests are unremarkable, then FCP is the likely etiology for patient's symptoms. Thus, establishing the diagnosis of FCP based on the Rome IV criteria requires a series of invasive tests and a therapeutic trial. Figure summarizes 
Table 2. Diagnostic Tests for Functional Chest Pain According to Rome IV Criteria

\begin{tabular}{|c|c|c|c|}
\hline Test & $\begin{array}{l}\text { Pathophysiological } \\
\text { mechanism to exclude }\end{array}$ & Benefits & Limits \\
\hline PPI test & GERD & Low cost & Dose and duration not determined \\
\hline $\begin{array}{l}\text { Upper endoscopy with } \\
\text { esophageal biopsies }\end{array}$ & GERD/EoE & $\begin{array}{l}\text { In presence of alarm symptoms rules out } \\
\text { structural abnormalities }\end{array}$ & $\begin{array}{l}\text { Needs sedation, variable cost- } \\
\text { benefit }\end{array}$ \\
\hline Reflux testing & GERD/reflux hypersensitivity & $\begin{array}{l}\text { Wireless } \mathrm{pH} \text { capsule allows up to } 96 \mathrm{hr} \\
\text { measurement. } \mathrm{pH} \text {-impedance detects acid/ } \\
\text { nonacid/gas/liquid reflux }\end{array}$ & Uncomfortable, invasive, costly \\
\hline Esophageal manometry & $\begin{array}{l}\text { Major esophageal motor } \\
\text { disorder }\end{array}$ & $\begin{array}{l}\text { Gold standard for diagnosing motor disorders. } \\
\text { In some of them defines treatment }\end{array}$ & Uncomfortable, invasive, costly \\
\hline
\end{tabular}

PPI, proton pump inhibitor; GERD, gastroesophageal reflux disease; EoE, eosinophilic esophagitis.

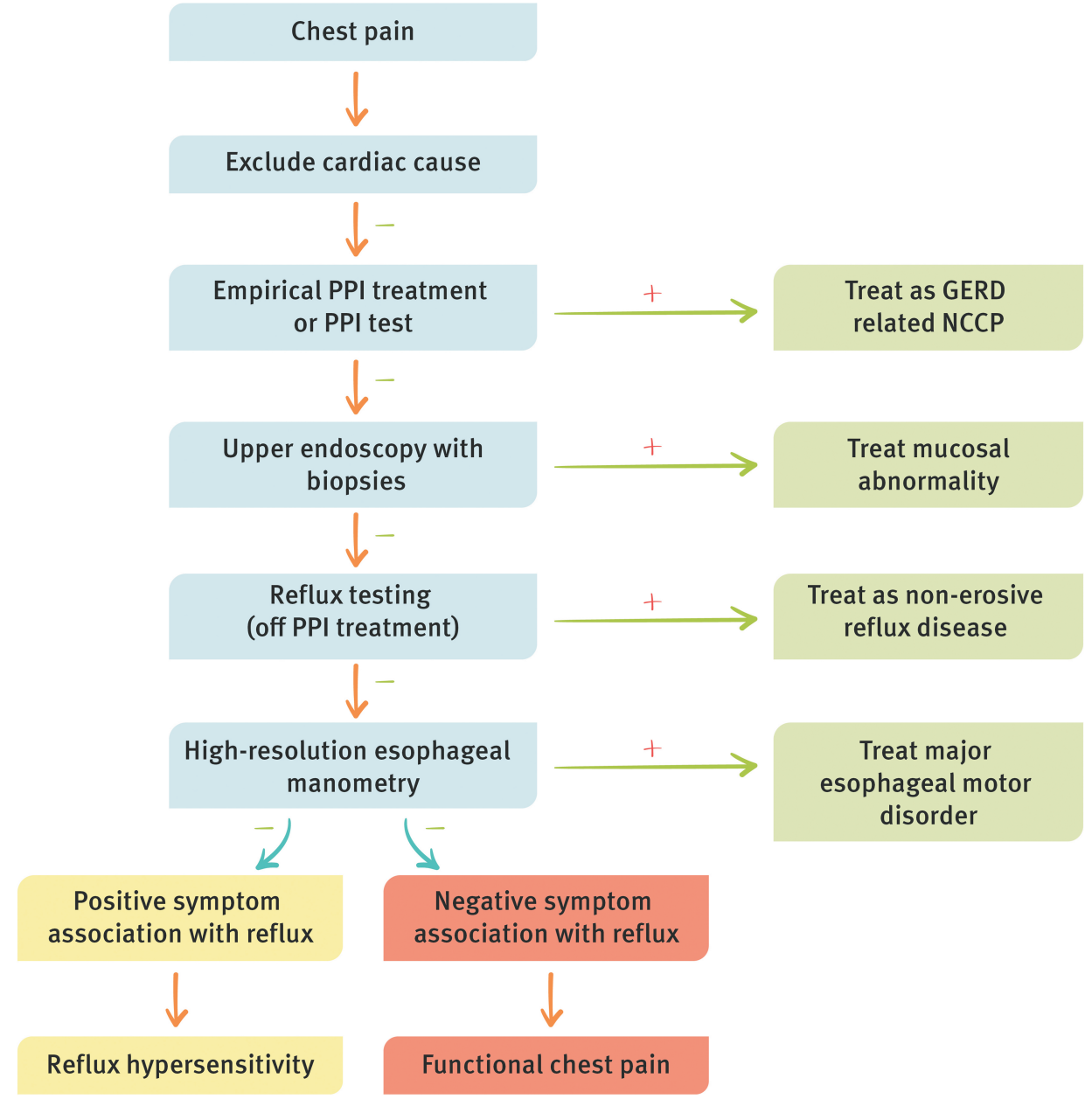

Figure. Diagnostic algorithm of patients with functional chest pain. PPI, proton pump inhibitor; GERD, gastroesophageal reflux disease; NCCP, noncardiac chest pain. the current management of FCP as was endorsed by the Rome IV functional esophageal disorders committee.

\section{Proton Pump Inhibitor Trial}

It has been demonstrated that between $10.0-42.0 \%$ of the
NCCP patients have erosive esophagitis on upper endoscopy and 21.0-53.0\% an abnormal esophageal acid exposure on reflux testing. ${ }^{13}$ Consequently, a PPI trial is indicated as the first step in the diagnosis algorithm of FCP (Figure). The PPI trial could be delivered as an empirical PPI therapy or as a PPI test. 
Thus far, 2 PPI therapeutic trials in NCCP have been reported in the literature. In one study, 34 patients with NCCP were randomized to receive either omeprazole $20 \mathrm{mg}$ twice daily or placebo for a period of 8 weeks. ${ }^{18}$ Patients receiving omeprazole demonstrated a significant symptom improvement $(81.0 \%)$ as compared to those receiving placebo $(6.0 \%, P=0.001)$. In addition, patients receiving omeprazole showed a significant improvement in chest pain severity and decrease in fraction of days with chest pain as compared with placebo $(40.7 \pm 8.1 \%$ vs $14.8 \pm 8.2 \%$ and $39 \pm$ $7.2 \%$ vs $10 \pm 6.9 \%$, respectively; $P<0.05$ ). In another double blind, parallel group, placebo-controlled trial, the authors randomized 599 NCCP patients to either esomeprazole $40 \mathrm{mg}$ twice daily versus placebo. ${ }^{19}$ Overall, treatment with esomeprazole was more effective than placebo ( $33.0 \%$ vs $25.0 \%, P=0.035)$ with the number needed to treat of 12 .

Another type of a PPI trial would be the PPI test, defined as a short course of high dose PPI therapy. ${ }^{20}$ The doses used in PPI test trials depended on the type of PPI utilized and included, 40-80 mg for omeprazole, 30-90 mg for lansoprazole, $40 \mathrm{mg}$ for rabeprazole, and $40 \mathrm{mg}$ for esomeprazole over a duration of 1-28 days (mostly for 1-2 weeks). ${ }^{21-34}$ The sensitivity and specificity of the PPI test in different studies ranged from $69.0-95.0 \%$ and $67.0-86.0 \%$, respectively. Overall, the PPI test is a simple, highly sensitive, and cost effective test for diagnosing GERD-related NCCP.

\section{Upper Endoscopy}

Diagnosis of FCP requires an upper endoscopy and if the esophageal mucosa is normal then biopsies should be obtained to rule out eosinophilic or lymphocytic esophagitis. ${ }^{2}$ In general, an initial workup with an upper endoscopy is commonly offered to patients with NCCP and alarm symptoms, such as dysphagia, odynophagia, anorexia, weight loss, and gastrointestinal bleeding. ${ }^{11}$ In patients without alarm symptoms, the PPI test or empiric treatment with a PPI should be considered first, and in those who demonstrate lack of response to treatment then upper endoscopy with possible biopsies should be considered. ${ }^{2}$

In clinical practice, patients with NCCP commonly undergo an upper endoscopy as the first diagnostic test when referred to a gastroenterologist. ${ }^{35}$ However, upper endoscopy has a variable rate of diagnostic yield in NCCP. Mucosal findings that are mostly consistent with acid peptic disorders can be found in $10.0-42.0 \%$ of the NCCP patients. ${ }^{36-40}$ In the largest endoscopic study thus far of 3688 consecutive NCCP patients, the authors demonstrated esophageal anatomic findings in $44.0 \%$ of the patients. ${ }^{35}$ They included hiatal hernia (28.6\%), erosive esophagitis (19.4\%), Barrett's esophagus
(4.4\%), stricture or stenosis (3.6\%), and peptic ulcer (2.0\%).

Esophageal neoplasia is rarely presented with chest pain alone. In one study of patients presenting with esophageal cancer, less than $1.0 \%$ reported chest pain solely. ${ }^{41}$

Overall, most NCCP patients, who undergo upper endoscopy, will demonstrate normal esophageal mucosa and upper gut anatomy. Biopsies to exclude eosinophilic or lymphocytic esophagitis should be performed in these patients. This recommendation is based on a study demonstrating that up to $14.0 \%$ of patients undergoing upper endoscopy for $\mathrm{NCCP}$ are found to have abnormal eosinophilic infiltrates on their esophageal biopsies. ${ }^{42}$

\section{Reflux Testing}

In patients with chest pains who demonstrated a negative response to a PPI trial and an unremarkable upper endoscopy with esophageal biopsies, reflux testing, and esophageal manometry are recommended as next diagnostic steps. ${ }^{2}$ Diagnosis of FCP requires for the former test to be negative and the latter test not to demonstrate a major esophageal motor disorder. ${ }^{43}$

It is preferable that the reflux testing is performed off PPI treatment for at least 7 days with a wireless $\mathrm{pH}$ capsule, which can measure today esophageal acid exposure over a period of 96 hours. In places where the wireless $\mathrm{pH}$ capsule is not available, it could be substituted with ambulatory 24 -hour esophageal $\mathrm{pH}$ monitoring or the $\mathrm{pH}$-impedance test off PPI treatment. ${ }^{13}$

Studies using the ambulatory 24-hour esophageal $\mathrm{pH}$ test in patients with NCCP off PPI treatment have demonstrated that between 21.0-53.0\% have an abnormal esophageal acid exposure, and between 12.0-50.0\% have a positive correlation between their chest pain and acid reflux events. ${ }^{4455}$ The wireless $\mathrm{pH}$ capsule, which can provide an extended measurement of esophageal acid exposure for up to 96 hours, has been shown to increase the yield of the $\mathrm{pH}$ test in detecting GERD in NCCP patients. In one study there was a $10.0 \%$ gain in detecting abnormal esophageal acid exposure at least in one of the study days and $7.3 \%$ increase in the number of patients reporting chest pain during the 48 -hour test. ${ }^{56}$ In addition, the number of documented chest pain episodes doubled from 1 day to 2 days and there was a $21.0 \%$ increase in the number of patients with positive symptom association probability.

Very few studies evaluated the additional value that $\mathrm{pH}-$ impedance provides in NCCP patients over the other reflux testing modalities. The test was able to show that reflux episodes associated with chest pain were more likely to reach the proximal esophagus and had a longer volume clearance time than reflux episodes not associated with chest pain. ${ }^{57}$ Interestingly, reflux events associated with 
chest pains were more often acidic. Another advantage of the $\mathrm{pH}$ impedance test is the use of baseline mucosal impedance as a surrogate marker for mucosal permeability. In one study it was demonstrated that baseline mucosal impedance in the distal esophagus of patients with GERD-related NCCP was significantly lower than in subjects with non-GERD-related $\mathrm{NCCP}^{58}$ In contrast, there was no difference in baseline mucosal impedance values between the 2 groups in the proximal esophagus, although it was significantly lower than healthy volunteers. However, for diagnosing FCP, the $\mathrm{pH}$-impedance test and metrics like basal mucosal impedance are currently not required.

\section{Esophageal Manometry}

Assessment of esophageal function, using high-resolution esophageal manometry, should be pursued prior diagnosing FCP in NCCP patients with normal reflux testing. The purpose of the test is to exclude major esophageal motor disorders, including achalasia, esophagogastric junction outflow obstruction, absent contractility, distal esophageal spasm, and jackhammer esophagus. ${ }^{2}$ The presence of ineffective esophageal motility or fragmented peristalsis does not exclude the diagnosis of FCP.

Studies have shown that most NCCP patients undergoing esophageal manometry (up to $70.0 \%$ ) demonstrate normal esophageal function. ${ }^{59-61}$ While hypercontractile esophageal motor disorders have been proposed to be the main underlying cause for esophageal related chest pain, studies have demonstrated that hypotensive esophageal motor disorders are the most common findings in NCCP patients undergoing esophageal manometry. Recently, Akinsiku et $\mathrm{al}^{61}$ have demonstrated that hypotensive lower esophageal sphincter was the most common motility disorder identified by conventional manometry (27.3\%), and ineffective esophageal motility was the most common esophageal motor disorder identified by high-resolution esophageal manometry $(25.3 \%)$.

The nature of the relationship between identified esophageal motor disorder and chest pain remains to be elucidated. Importantly, patients rarely report chest pain during esophageal manometry, when these motor abnormalities are diagnosed. ${ }^{11,13}$ In addition, therapies aimed at improving the identified esophageal motor disorder in NCCP patients have not yielded consistent results. ${ }^{13}$ Consequently, it has been hypothesized that the esophageal motility disorders diagnosed in NCCP patients may represent a marker for a general sensory-motor abnormality or possibly just an epiphenomenon. $^{13,43}$

\section{Sensory Testing}

The role of sensory testing in FCP has been scarcely studied. Some of the tests were introduced to reproduce patient's chest pain and others to assess for the presence of esophageal hypersensitivity. ${ }^{62}$ However, the different sensory tests (Table 3) have not been standardized and various protocols have been used in different studies. Furthermore, the tests are invasive, uncomfortable and we are still devoid of any evidence that a positive test can direct a specific treatment or predict therapeutic outcome. ${ }^{63}$

The original acid perfusion test (Bernstein test) was intended to discriminate between cardiac and esophageal pain. ${ }^{64}$ The test has been shown to be highly specific but with a relatively low sensitivity (7.0-60.0\%). Later modifications to the test have converted it to a sensory testing, assessing for the presence of esophageal hypersensitivity. ${ }^{65}$ Balloon distention was also originally introduced as a tool to discriminate between esophageal and cardiac pain with a limited sensitivity that ranged from 5.0-75.0\%..$^{66,67}$ Later, the technique has evolved to assess for the presence of esophageal hypersensitivity. However, as with the acid perfusion test, protocols were not standardized, and different equipment was used. ${ }^{14}$ Moreover, the test is invasive, painful and has not been shown to predict therapeutic outcome.

Impedance planimetry, using dynamic balloon distensions, has been utilized in FCP to assess esophageal sensory thresholds and biomechanical properties. ${ }^{68}$ In one study, the authors demonstrated that FCP patients have lower perception thresholds for pain, larger cross-sectional esophageal area, decreased esophageal wall strain, and reduced distensability. ${ }^{68}$

Electrical stimulation, thermal stimulation, and multimodal techniques that provide a battery of stimulation tests (electrical, acid, balloon, and thermal) have been used primarily as research tools to assess for esophageal hypersensitivity in NCCP patients. ${ }^{69}$

\section{Psychological Evaluation}

Psychological comorbidity is very common in patients with FCP, affecting up to $75.0 \% .^{70}$ Depression, anxiety, neuroticism, and

Table 3. Sensory Testing in Functional Chest Pain

- Acid perfusion test

- Balloon distention test

- Impedance planimetry

- Electrical stimulation

- Thermal stimulation

- Multi-modal stimulation test (thermal, balloon, and electrical) 
hypochondrial behavior have been described in these patients. ${ }^{2,13,70,71}$ In addition, panic attacks are commonly associated with chest pain, driving patients to seek medical attention.

Psychological evaluation of patients with FCP is paramount for improving patient's response to any therapeutic intervention, increase their quality of life, and reduce perceived severity of the disease. If available, patients should be referred to a psychiatrist or a psychologist, with interest in FGIDs.

\section{Treatment}

The treatment goals in patients with FCP are 2-fold; symptoms control and improvement in quality of life. ${ }^{72}$ The therapeutic modalities include medications, primarily neuromodulators, alternative and complimentary medicine, and psychological intervention. There are very few therapeutic trials that only addressed FCP patients and thus most of the current therapeutic recommendations for this disorder are extrapolated from studies performed in NCCP patients. ${ }^{73}$

Neuromodulators are the mainstay of treatment for patients with FCP as they are for NCCP patients. They include tricyclic antidepressants (TCAs), selective serotonin reuptake inhibitors (SSRIs), serotonin-norepinephrine reuptake inhibitors (SNRIs), adenosine antagonists, trazadone, serotonin $\left(5-\mathrm{HT}_{3}\right)$ receptor antagonists, serotonin $\left(5-\mathrm{HT}_{4}\right)$ receptor agonists, octreotide, gabapentin, pregabalin, and cannabinoid receptors agonist. ${ }^{74}$ Table 4 summarizes the neuromodulators that were studied in randomized controlled trials of patients with NCCP and FCP.

A systematic review of antidepressants therapeutic trials in NCCP patients have identified 6 randomized, placebo-controlled trials. ${ }^{75}$ The medications analyzed were paroxetine (2 studies), sertraline, imipramine, venlafaxine, and trazodone (1 study each). The analysis showed a significant heterogeneity among the studies with several important study limitations. However, there was a

Table 4. Pain Modulators for the Treatment of Functional Chest Pain

\begin{tabular}{|c|c|c|c|c|c|}
\hline Class of drug & Disorder & Dose & $\mathrm{N}$ & $\begin{array}{l}\text { Duration } \\
\text { (week) }\end{array}$ & Results \\
\hline \multicolumn{6}{|l|}{ TCAs } \\
\hline Imipramine ${ }^{45}$ & $\mathrm{NCCP}$ & $50 \mathrm{mg} /$ day & 60 & 3 & Reduction in chest pain frequency and intensity \\
\hline Imipramine $^{46}$ & $\mathrm{NCCP}$ & $50 \mathrm{mg} /$ day & 18 & 5 & $\begin{array}{l}\text { Decreased median total number of chest pain episodes and } \\
\text { number of moderate severity of chest pain episodes }\end{array}$ \\
\hline Amitriptyline ${ }^{47}$ & $\mathrm{FCP}$ & $\begin{array}{l}10 \mathrm{mg}+ \\
\text { rabeprazole } 20 \mathrm{mg}\end{array}$ & 40 & 8 & Greater improvement than rabeprazole alone \\
\hline \multicolumn{6}{|l|}{ SSRIs } \\
\hline Sertraline ${ }^{49}$ & $\mathrm{NCCP}$ & $50-200 \mathrm{mg} /$ day & 115 & 34 & $\begin{array}{l}\text { Significantly reduced initial and sustained pain intensity } \\
\text { and pain unpleasantness }\end{array}$ \\
\hline Sertraline ${ }^{48}$ & $\mathrm{NCCP}$ & $50-200 \mathrm{mg} /$ day & 30 & 8 & $\begin{array}{l}\text { Statistically significant reduction in pain compared with } \\
\text { those who were receiving placebo. }\end{array}$ \\
\hline Paroxetine $^{51}$ & $\mathrm{NCCP}$ & $10-40 \mathrm{mg} /$ day & 69 & 16 & $\begin{array}{l}\text { Percentage of responders between } \mathrm{CBT} \text { and paroxetine } \\
\text { and paroxetine and placebo was not statistically signifi- } \\
\text { cant. }\end{array}$ \\
\hline Paroxetine $^{50}$ & $\mathrm{NCCP}$ & $10-50 \mathrm{mg} /$ day & 50 & 8 & $\begin{array}{l}\text { Paroxetine-treated patients showed greater }(P<0.05) \text { im- } \\
\text { provement. }\end{array}$ \\
\hline \multicolumn{6}{|r|}{ 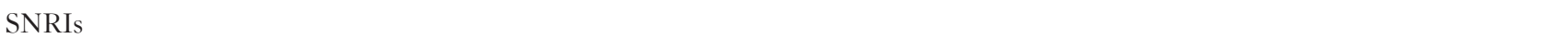 } \\
\hline Venlafaxine ${ }^{54}$ & $\mathrm{FCP}$ & $75 \mathrm{mg} /$ day & 43 & 4 & $\begin{array}{l}\text { Positive response was observed in } 52.0 \% \text { of patients dur- } \\
\text { ing venlafaxine treatment. }\end{array}$ \\
\hline \multicolumn{6}{|l|}{ Other } \\
\hline Trazodone $e^{53}$ & $\mathrm{NCCP}$ & $100-150 \mathrm{mg} /$ day & 29 & 6 & $\begin{array}{l}\text { Significantly greater global improvement, reduction in rat- } \\
\text { ings of chest pain in both treatment groups }\end{array}$ \\
\hline Theophyline $e^{60}$ & $\mathrm{ECP}$ & $400 \mathrm{mg} /$ day & 24 & 4 & $\begin{array}{l}\text { Decrease in number of painful days, chest pain episodes, } \\
\text { pain duration, and its severity }\end{array}$ \\
\hline Dronabinol $^{58}$ & $\mathrm{FCP}$ & $10 \mathrm{mg} /$ day & 13 & 4 & $\begin{array}{l}\text { Increased pain threshold and reduced pain intensity vs } \\
\text { placebo }\end{array}$ \\
\hline
\end{tabular}

TCAs, tricyclic antidepressants; SSRIs, selective serotonin reuptake inhibitors; SNRIs, serotonin norepinephrine reuptake inhibitors; NCCP, noncardiac chest pain; FCP, functional chest pain; ECP, esophageal chest pain; CBT, cognitive behavioral therapy. 
statistically significant reduction in chest pain with sertraline $(63.0 \%$ vs $15.0 \%, P=0.020)$, imipramine (52.0\% vs $1.0 \%, P=0.030$ ), and venlafaxine $(50.0 \%$ vs $10.0 \%, P<0.001)$. Clinical global improvement also significantly improved in patients receiving venlafaxine, sertraline, paroxetine, and trazodone. The improvement in chest pain symptoms was independent of improvement in depression scores. The percentage of reported adverse effects was relatively high compared with the placebo group and was the reason for discontinuation of the trial in up to $53.0 \%$ of the patients. The study concluded that there was modest evidence for the benefit of antidepressants in reducing NCCP and improving patients' general health.

\section{Tricyclic Antidepressants}

TCAs are commonly used as neuromodulators in patients with FCP, despite the presence of only 2 randomized, double blind, placebo-controlled trials. ${ }^{72}$ Most of the available data about their value in NCCP and FCP originates from retrospective, cohort studies. Overall, TCAs demonstrate an effect on esophageal pain in both healthy subjects and patients with esophageal disorders associated with chest pain. ${ }^{74}$ The TCAs are composed from compounds that demonstrated different affinity to 4 receptors, noradrenalin, serotonin, histamine-1, and acetylcholine. ${ }^{76}$ The main feature of TCAs, which is likely responsible for their analgesic effect is a variable combination of serotonin and noradrenalin reuptake inhibition effect. $^{77}$

In 2 randomized, double blind, placebo controlled trails, imipramine was demonstrated to improve symptoms in NCCP patients. In the first study, imipramine $50 \mathrm{mg}$ once daily was compared with clonidine $0.1 \mathrm{mg}$ or placebo once daily. ${ }^{78}$ Only imipramine demonstrated significant reduction in chest pain frequency $(\sim 50.0 \%)$ and right ventricular sensitivity as compared with placebo. Both imipramine and clonidine significantly improved chest pain intensity as compared with placebo. Interestingly, there was no effect of any of the therapeutic arms on esophageal sensitivity to balloon distention. In a second randomized, double-blind cross over study, comparing imipramine $50 \mathrm{mg}$ daily to placebo, the authors demonstrated that the total number of chest pain episodes was significantly lower in the imipramine group $(\mathrm{n}=11)$ as compared to the placebo group ( $\mathrm{n}$ $=21, P=0.01$ ) after 5 weeks of treatment. ${ }^{79}$ However, there was no change in any of the quality of life domains assessed, likely due to a very high incidence rate of side effects with imipramine as compared with placebo $(83.0 \%$ vs $44.0 \%, P=0.010)$. In another study, patients with FCP were randomized, using an open label design, to rabeprazole $20 \mathrm{mg}$ daily plus low dose amitriptyline $10 \mathrm{mg}$ at bedtime versus double dose rabeprazole $20 \mathrm{mg} .{ }^{80}$ After 8 weeks of treatment, $71.0 \%$ of those receiving rabeprazole plus amitriptyline demonstrated greater than $50.0 \%$ global symptom improvement as compared with $26.0 \%$ of the patients receiving double dose rabeprazole $(P=0.008)$. Furthermore, those that received the amitriptyline also showed a significantly greater improvement in scores of bodily pain and general health perception as compared to the double dose rabeprazole group ( $P=0.031$ and $P=0.010$, respectively).

In functional esophageal disorders and specifically in FCP, TCAs are often given in non-mood-altering doses and at bed time (improve sleep experience). ${ }^{81}$ The initial dose range that has been reported in the literature is between $10 \mathrm{mg}$ to $50 \mathrm{mg}$ daily and maximal dose range is between $25 \mathrm{mg}$ to $150 \mathrm{mg}$ daily. Our TCA dosing approach in FCP patients has followed the rule of "low and slow." Starting dose is commonly $10-25 \mathrm{mg}$ at bedtime and may increase by $10-25 \mathrm{mg}$ increments every week for up to $50-75 \mathrm{mg}$ daily. $^{74}$ TCAs may be combined with SSRIs. If one TCA does not improve patient's symptoms then another TCA can be used, because of the different affinity TCAs demonstrate to their respective receptors. If side effects develop then a lower dose of the same TCA or another TCA can be entertained.

Side effects are very common and may develop in 30.0-100.0\% of the patients receiving TCAs. ${ }^{82}$ The side effects of TCAs are often related to the receptors to which they demonstrate the most affinity. Tertiary amines (amitriptyline, imipramine, etc) are more commonly associated with side effects as compared with secondary amines (nortriptyline, desipramine, etc) due to greater receptor affinity. ${ }^{74}$ Side effects of TCAs include dizziness, somnolence, drowsiness, lightheadedness, jittery feeling, weakness, urinary retention, dry mouth, constipation, blurred vision, flushing, orthostatic hypotension, confusion, mental status change, sexual dysfunction, arrhythmias, and weight gain. ${ }^{74,81}$ TCAs should be prescribed with caution in elderly male patients, especially those with benign prostate hypertrophy and patients with cardiovascular disease. TCAs should be avoided in patients with cardiac bundle branch block or prolonged QT interval. ${ }^{77}$ The somnolence effect of TCAs has been used to improve patient's sleep experience, which has been shown to be analgesic and thus part of FCP management.

\section{Selective Serotonin Reuptake Inhibitors}

This class of drugs selectively blocks the presynaptic serotonin transporter and thus boosts serotonin neurotransmission. ${ }^{77}$ There are 4 randomized, placebo-controlled trials using SSRIs in patients with NCCP or FCP. Paroxetine was evaluated in 2 double blind placebo-controlled trials. In the first study, NCCP patients were 
randomized to paroxetine versus placebo. After 8 weeks of treatment, those receiving paroxetine demonstrated significant improvement in the clinical global impressions scale as compared to those receiving placebo. ${ }^{83}$ Both paroxetine and placebo-treated patients improved to a similar extent on self-related pain measures. In the second study, patients were randomized to paroxetine or placebo in a double-blind fashion and cognitive behavioral therapy (CBT). ${ }^{84}$ In this study, CBT was significantly better as compared to paroxetine or placebo in reducing pain and heart focused anxiety.

Sertraline, at doses of $50 \mathrm{mg}$ to $200 \mathrm{mg}$, depends on the clinical response, significantly reduced chest pain scores $(P=0.020)$, with chest pain scores decreasing by approximately 0.2 units for each week of the study. ${ }^{85}$ In addition, the SF-36 sub scores of general health, also significantly improved at the end of treatment period. In another study, NCCP patients undergoing coping skills training either alone or with sertraline demonstrated a significant reduction in pain intensity and pain unpleasantness as compared with sertraline or placebo alone. ${ }^{86}$ The combination of coping skills training and sertraline was found to also reduce pain catastrophizing and anxiety.

A meta-analysis of all randomized controlled trials comparing SSRIs to placebo in patients with NCCP demonstrated that SSRIs were not superior to placebo in improving chest pain or depression symptoms. ${ }^{87}$ The authors pointed out to the need of larger trials with longer follow-up periods.

SSRIs may be associated with a variety of side effects, including nausea, vomiting, anorexia, diarrhea, decreased libido, delayed ejaculation, somnolence, insomnia, drowsiness, fatigue, headache, restlessness, and hyperhidrosis. ${ }^{74}$ The rate of side effects may be as high as $74.0 \% .^{75}$ In NCCP patients, sertraline can be given in doses ranging from $50 \mathrm{mg}$ to $200 \mathrm{mg}$ and paroxetine in doses ranging from $5 \mathrm{mg}$ to $50 \mathrm{mg}$. ${ }^{81}$ In a recent Rome foundation working report, the authors pointed out that SSRIs have shown some benefit for esophageal pain. ${ }^{77}$

\section{Serotonin Noradrenaline Reuptake Inhibitors}

The SNRIs have variable blocking effect on the reuptake of serotonin and noradrenalin and thereby on boosting of serotonin and noradrenalin neurotransmission. ${ }^{77}$ Due to lack of anti-muscarinic effect and affinity to histamine receptors in the brain, this class of drugs has less undesirable side effects. ${ }^{88}$ Venlafaxine, the first SNRI to be marketed, at doses of up to $222 \mathrm{mg}$ act only as a potent serotonin reuptake inhibitor. ${ }^{89}$ In a randomized, double-blind placebocontrolled trial, venlafaxine $75 \mathrm{mg}$ at bedtime was compared with placebo in relieving symptoms of FCP patients. ${ }^{90}$ The study demonstrated that $52.0 \%$ of the $\mathrm{FCP}$ patients receiving venlafaxine as compared with $4.0 \%$ of those receiving placebo, reported symptom improvement by more than $50.0 \%(P<0.001)$.

Side effects of venlafaxine include sleep disturbances, anorexia, nausea, dry mouth, somnolence, dizziness, and abnormal ejaculation. Venlafaxine is contraindicated in patients who are concomitantly treated with monoamine oxidase inhibitors.

\section{Other Neuromodulators}

Several other neuromodulators were assessed, either in a randomized controlled trial or retrospective design, in NCCP patients. Trazadone, a serotonin modulator, was shown to be effective in treating patients with NCCP and esophageal motor disorders. ${ }^{91,92}$ However, with the new Rome IV criteria, many of these patients would not have been considered as having FCP because of the presence of major esophageal motor disorder. Ondansetron, a serotonin $\left(5-\mathrm{HT}_{3}\right)$ receptor antagonist, has been shown to increase perception thresholds for pain in NCCP patients, but its effect on NCCP symptoms was not studied. ${ }^{93}$

Theophylline, an adenosine antagonist, has been shown to increase perception thresholds for pain in patients undergoing esophageal balloon distension. ${ }^{94,95}$ In a randomized placebo-controlled trial, the authors demonstrated that theophylline $200 \mathrm{mg}$ twice daily was significantly better compared to placebo in reducing symptoms (58.0\% vs $6.0 \%, P<0.02)$, chest pain episodes $(P=0.025)$, duration of symptoms $(P=0.002)$, and severity of symptoms $(P=$ $0.031) .^{94}$ Theophylline is not commonly used anymore, primarily due to its side effect profile.

Dronabinol, a synthetic agonist of both cannabinoid receptors CB1 and CB2, has been shown to have a visceral anti-nociceptive effect. ${ }^{96}$ A study which included 19 FCP patients, demonstrated that 10 of them, who received dronabinol $5 \mathrm{mg}$ twice daily for 4 weeks, reported decreased pain perception at different sequential balloon inflations, had an improvement in pain intensity and odynophagia frequency and a trend towards improvement in chest pain episodes. $^{97}$

\section{Alternative Medicine}

Different alternative and complimentary medicine approaches may potentially have a therapeutic effect in patients with FCP. Thus far, only energy healing, using Johrei therapy, was studied in FCP patients. In one study patients with $\mathrm{FCP}$ were randomized to Johrei therapy versus wait list (no intervention). After 18 Johrei sessions over a 6 week-period, those that received energy healing showed a significant reduction in symptom intensity score post treatment $(P$ $=0.002$ ), while those receiving no intervention (wait list) demon- 
strated no improvement during the same period of time. ${ }^{98}$ Johrei was very well tolerated by patients.

\section{Psychological Intervention}

Several psychological techniques have been shown to be efficacious in patients with NCCP. There are no specific studies that targeted only patients with FCP. CBT have been studied extensively in NCCP patients, demonstrating improvement and even resolution of chest pain symptoms, improvement in health-related quality of life, and various psychological parameters. ${ }^{84,99-104}$ Other psychological interventions that have been shown to improve symptoms in NCCP patients include hypnotherapy, group psychological treatment, and coping skills. ${ }^{86,15,106}$

Hypnotherapy received more attention as an intervention for a variety of functional esophageal and other bowel disorders. In one small sample study, NCCP patients were randomized to hypnotherapy or supportive therapy plus placebo. ${ }^{105}$ Patients received 12 sessions of 1 of the 2 interventions over a 17-week period. More patients who received hypnotherapy demonstrated a significant global improvement in chest pain $(P=0.008)$ and reduction in chest pain intensity scores $(P=0.046)$, as compared to those who received supportive therapy plus placebo medication.

\section{Conclusions}

Current diagnosis of FCP follows the new criteria proposed by the Rome IV committee for functional esophageal disorders. All patients with NCCP should be evaluated for GERD, using the PPI test or empirical PPI trial and $\mathrm{pH}$-impedance test or wireless $\mathrm{pH}$ capsule. An upper endoscopy can help to exclude esophageal and gastric mucosal abnormalities, as well as eosinophilic esophagitis using a disease-related biopsy protocol. Esophageal manometry is required to exclude major esophageal motor disorders.

The mainstay treatment of patients with FCP are the neuromodulators that primarily include anti-depressants (TCAs, SSRIs, and SNRIs), as well as other less commonly used and studied medications like theophylline and ondansetron. Psychological intervention, especially CBT, may be used solely or in combination with neuromodulators. Other psychological interventions like hypnotherapy and alternative medicine approaches may be considered as well. Unfortunately, most of the data on the management of FCP originates from NCCP studies, which did not attempt to specifically identify the FCP patients. Thus, future studies are needed to evaluate the proper management of Rome IV defined FCP patients.

\section{Financial support: None.}

Conflicts of interest: None.

Author contributions: Ronnie Fass and Jose Tawil: performed literature search and help write the manuscript; and Fahmi Shibli: help write the manuscript.

\section{References}

1. Schmulson M. How to use Rome IV criteria in the evaluation of esophageal disorders. Curr Opin Gastroenterol 2018;34:258-265.

2. Aziz Q, Fass R, Gyawali CP, Miwa H, Pandolfino JE, Zerbib F. Functional esophageal disorders. Gastroenterology 2016;150:1368-1379.

3. Coen SJ, Kano M, Farmer AD, et al. Neuroticism influences brain activity during the experience of visceral pain. Gastroenterology 2011;141:909-917, e1.

4. Sharma A, Van Oudenhove L, Paine P, Gregory L, Aziz Q. Anxiety increases acid-induced esophageal hyperalgesia. Psychosom Med 2010;72:802-809

5. Farmer AD, Ruffle JK, Aziz Q. The role of esophageal hypersensitivity in functional esophageal disorders. J Clin Gastroenterol 2017;51:91-99.

6. Fass R, Achem SR. Noncardiac chest pain: epidemiology, natural course and pathogenesis. J Neurogastroenterol Motil 2011;17:110-123.

7. Palsson OS, Whitehead WE, van Tilburg MA, et al. Rome IV diagnostic questionnaires and tables for investigators and clinicians. Gastroenterology 2016;150:1481-1491.

8. Galmiche JP, Clouse RE, Bálint A, et al. Functional esophageal disorders. Gastroenterology 2006;130:1459-1465.

9. Locke GR 3rd, Talley NJ, Fett SL, Zinsmeister AR, Melton LJ 3rd. Prevalence and clinical spectrum of gastroesophageal reflux: a population-based study in Olmsted County, Minnesota. Gastroenterology 1997;112:1448-1456.

10. Eslick GD, Jones MP, Talley NJ. Non-cardiac chest pain: prevalence, risk factors, impact and consulting - a population-based study. Aliment Pharmacol Ther 2003;17:1115-1124.

11. Fass R, Dickman R. Non-cardiac chest pain: an update. Neurogastroenterol Motil 2006;18:408-417.

12. Gomez Cifuentes J, Lopez R, Thota PN. Factors predictive of gastroesophageal reflux disease and esophageal motility disorders in patients with non-cardiac chest pain. Scand J Gastroenterol 2018;53:643-649.

13. Fass R, Achem SR. Noncardiac chest pain: diagnostic evaluation. Dis Esophagus 2012;25:89-101.

14. Yamasaki T, Fass R. Noncardiac chest pain: diagnosis and management. Curr Opin Gastroenterol 2017;33:293-300.

15. Dammen T, Arnesen H, Ekeberg O, Friis S. Psychological factors, pain attribution and medical morbidity in chest-pain patients with and without coronary artery disease. Gen Hosp Psychiatry. 2004;26:463-469.

16. White KS, Raffa SD, Jakle KR, et al. Morbidity of DSM-IV Axis I disorders in patients with noncardiac chest pain: psychiatric morbidity linked with increased pain and health care utilization. J Consult Clin 
Psychol 2008;76:422-430

17. Fass R, Navarro-Rodriguez T. Noncardiac chest pain.J Clin Gastroenterol 2008;42:636-646.

18. Achem SR, Kolts BE, Wears R, Burton L, Richter JE. Chest pain associated with nutcracker esophagus: a preliminary study of the role of gastroesophageal reflux. Am J Gastroenterol 1993;88:187-192.

19. Flook NW, Moayyedi P, Dent J, et al. Acid-suppressive therapy with esomeprazole for relief of unexplained chest pain in primary care: a randomized, double-blind, placebo-controlled trial. Am J Gastroenterol 2013;108:56-64.

20. Gasiorowska A, Fass R. The proton pump inhibitor (PPI) test in GERD: does it still have a role? J Clin Gastroenterol 2008;42:867-874.

21. Schenk BE, Kuipers EJ, Klinkenberg-Knol EC, et al. Omeprazole as a diagnostic tool in gastroesophageal reflux disease. Am J Gastroenterol 1997;92:1997-2000.

22. Schindlbeck NE, Klauser AG, Voderholzer WA, Müller-Lissner SA. Empiric therapy for gastroesophageal reflux disease. Arch Intern Med 1995; 155:1808-1812.

23. Johnsson F, Weywadt L, Solhaug JH, Hernqvist H, Bengtsson L. Oneweek omeprazole treatment in the diagnosis of gastro-oesophageal reflux disease. Scand J Gastroenterol 1998;33:15-20.

24. Fass R, Ofman JJ, Gralnek IM, et al. Clinical and economic assessment of the omeprazole test in patients with symptoms suggestive of gastroesophageal reflux disease. Arch Intern Med 1999;159:2161-2168.

25. Bate CM, Riley SA, Chapman RW, Durnin AT, Taylor MD. Evaluation of omeprazole as a cost-effective diagnostic test for gastro-oesophageal reflux disease. Aliment Pharmacol Ther 1999;13:59-66.

26. Juul-Hansen P, Rydning A, Jacobsen CD, Hansen T. High-dose proton-pump inhibitors as a diagnostic test of gastro-oesophageal reflux disease in endoscopic-negative patients. Scand J Gastroenterol 2001;36:806-810.

27. Squillace SJ. Single dose omeprazole as a test for non-cardiac chest pain. Gastroenterology 1993;104:197.

28. Young MF, Sanowski RA, Talbert GA, Herrison ME, Walker BE. Omeprazole administration as a test for gastroesophageal reflux. Gastroenterology 1992;102(4 Pt 2):192.

29. Pandak WM, Arezo S, Everett S, et al. Short course of omeprazole: a better first diagnostic approach to noncardiac chest pain than endoscopy, manometry, or 24-hour esophageal pH monitoring. J Clin Gastroenterol 2002;35:307-314.

30. Xia HH, Lai KC, Lam SK, et al. Symptomatic response to lansoprazole predicts abnormal acid reflux in endoscopy-negative patients with noncardiac chest pain. Aliment Pharmacol Ther 2003;17:369-377.

31. Bautista J, Fullerton H, Briseno M, Cui H, Fass R. The effect of an empirical trial of high-dose lansoprazole on symptom response of patients with non-cardiac chest pain--a randomized, double-blind, placebocontrolled, crossover trial. Aliment Pharmacol Ther 2004;19:11231130 .

32. Dickman R, Emmons S, Cui H, et al. The effect of a therapeutic trial of high-dose rabeprazole on symptom response of patients with non-cardiac chest pain: a randomized, double-blind, placebo-controlled, crossover trial. Aliment Pharmacol Ther 2005;22:547-555.
33. Fass R. Empirical trials in treatment of gastroesophageal reflux disease. Dig Dis 2000;18:20-26.

34. Husser D, Bollmann A, Kühne C, Molling J, Klein HU. Evaluation of noncardiac chest pain: diagnostic approach, coping strategies and quality of life. Eur J Pain 2006;10:51-55.

35. Dickman R, Mattek N, Holub J, Peters D, Fass R. Prevalence of upper gastrointestinal tract findings in patients with noncardiac chest pain versus those with gastroesophageal reflux disease (GERD)-related symptoms: results from a national endoscopic database. Am J Gastroenterol 2007; 102:1173-1179.

36. Hsia PC, Maher KA, Lewis JH, Cattau EL Jr, Fleischer DE, Benja$\min$ SB. Utility of upper endoscopy in the evaluation of noncardiac chest pain. Gastrointest Endosc. 1991;37:22-26.

37. Frøbert O, Funch-Jensen P, Jacobsen NO, Kruse A, Bagger JP. Upper endoscopy in patients with angina and normal coronary angiograms. Endoscopy 1995;27:365-370.

38. García-Compeán D, González MV, Galindo G, et al. Prevalence of gastroesophageal reflux disease in patients with extraesophageal symptoms referred from otolaryngology, allergy, and cardiology practices: a prospective study. Dig Dis 2000;18:178-182.

39. Wong WM, Lai KC, Lau CP, et al. Upper gastrointestinal evaluation of Chinese patients with non-cardiac chest pain. Aliment Pharmacol Ther 2002;16:465-471.

40. Battaglia E, Bassotti G, Buonafede G, et al. Noncardiac chest pain of esophageal origin in patients with and without coronary artery disease. Hepatogastroenterology 2005;52:792-795.

41. Gibbs JF, Rajput A, Chadha KS, et al The changing profile of esophageal cancer presentation and its implication for diagnosis. J Natl Med Assoc 2007;99:620-626.

42. Achem SR, Almansa C, Krishna M, et al. Oesophageal eosinophilic infiltration in patients with noncardiac chest pain. Aliment Pharmacol Ther 2011;33:1194-1201

43. Fass R, Pandolfino JE, Aziz Q, et al. Esophageal disorders. In: Kellow JE, eds. Rome IV diagnostic algorithms for common GI symptoms. Volume 1. 2nd ed. Raleigh: the Rome foundation 2016:1-24.

44. DeMeester TR, O’Sullivan GC, Bermudez G, Midell AI, Cimochowski GE, O'Drobinak J. Esophageal function in patients with angina-type chest pain and normal coronary angiograms. Ann Surg 1982;196:488498.

45. de Caestecker JS, Blackwell JN, Brown J, Heading RC. The oesophagus as a cause of recurrent chest pain: which patients should be investigated, and which tests should be used? Lancet 1985;2:1143-1146.

46. Janssens J, Vantrappen G, Ghillebert G. 24-hour recording of esophageal pressure and $\mathrm{pH}$ in patients with noncardiac chest pain. Gastroenterology 1986;90:1978-1984.

47. Schofield PM, Bennett DH, Whorwell PJ, et al. Exertional gastrooesophageal reflux: a mechanism for symptoms in patients with angina pectoris and normal coronary angiograms. Br Med J (Clin Res Ed) 1987;294:1459-1461.

48. Hewson EG, Dalton CB, Richter JE. Comparison of esophageal manometry, provocative testing, and ambulatory monitoring in patients with unexplained chest pain. Dig Dis Sci 1990;35:302-309. 
49. Soffer EE, Scalabrini P, Wingate DL. Spontaneous noncardiac chest pain: value of ambulatory esophageal $\mathrm{pH}$ and motility monitoring. Dig Dis Sci 1989;34:1651-1655.

50. Hewson EG, Sinclair JW, Dalton CB, Richter JE. Twenty-four-hour esophageal $\mathrm{pH}$ monitoring: the most useful test for evaluating noncardiac chest pain. Am J Med 1991;90:576-583.

51. Gastal OL, Castell JA, Castell DO. Frequency and site of gastroesophageal reflux in patients with chest symptoms. Studies using proximal and distal pH monitoring. Chest 1994;106:1793-1796.

52. Voskuil JH, Cramer MJ, Breumelhof R, Timmer R, Smout AJ. Prevalence of esophageal disorders in patients with chest pain newly referred to the cardiologist. Chest 1996;109:1210-1214.

53. Cooke RA, Anggiansah A, Chambers JB, Owen WJ. A prospective study of oesophageal function in patients with normal coronary angiograms and controls with angina. Gut 1998;42:323-329.

54. Ghillebert G, Janssens J, Vantrappen G, Nevens F, Piessens J. Ambulatory 24-hour intraoesophageal $\mathrm{pH}$ and pressure recordings $\mathrm{v}$ provocation tests in the diagnosis of chest pain of oesophageal origin. Gut 1990;31:738-744.

55. Paterson WG, Abdollah H, Beck IT, Da Costa LR. Ambulatory esophageal manometry, $\mathrm{pH}$-metry, and Holter ECG monitoring in patients with atypical chest pain. Dig Dis Sci 1993;38:795-802.

56. Prakash C, Clouse RE. Wireless $\mathrm{pH}$ monitoring in patients with noncardiac chest pain. Am J Gastroenterol 2006;101:446-452.

57. Herregods TVK, Bredenoord AJ, Oors JM, Bogte A, Smout AJPM. Determinants of the association between non-cardiac chest pain and reflux. Am J Gastroenterol 2017;112:1671-1677.

58. Min YW, Choi K, Pyo JH, Son HJ, Rhee PL. Impaired esophageal mucosal integrity may play a causative role in patients with nongastroesophageal reflux disease-related noncardiac chest pain. Medicine (Baltimore) 2015;94:e2295.

59. Katz PO, Dalton CB, Richter JE, Wu WC, Castell DO. Esophageal testing of patients with noncardiac chest pain or dysphagia: results of three years' experience with 1161 patients. Ann Intern Med 1987;106:593-597.

60. Dekel R, Pearson T, Wendel C, De Garmo P, Fennerty MB, Fass R. Assessment of oesophageal motor function in patients with dysphagia or chest pain - the clinical outcomes research initiative experience. Aliment Pharmacol Ther 2003;18:1083-1089.

61. Akinsiku O, Yamasaki T, Brunner S, Ganocy S, Fass R. High resolution vs conventional esophageal manometry in the assessment of esophageal motor disorders in patients with non-cardiac chest pain. Neurogastroenterol Motil 2018;30:e13282.

62. Fass R. Sensory testing of the esophagus. J Clin Gastroenterol 2004;38:628-641.

63. Fass R. Evaluation and diagnosis of noncardiac chest pain. Dis Mon 2008;54:627-641.

64. Bernstein LM, Baker LA. A clinical test for esophagitis. Gastroenterology 1958;34:760-781.

65. Fass R, Naliboff B, Higa L, et al. Differential effect of long-term esophageal acid exposure on mechanosensitivity and chemosensitivity in humans. Gastroenterology 1998;115:1363-1373.
66. Baylis JH, Kauntzer R, Trouncer JR. Observations on distension of the lower end of the oesophagus. Q J Med 1955;24:143-153.

67. Nasr I, Attaluri A, Coss-Adame E, Rao SS. Diagnostic utility of the oesophageal balloon distension test in the evaluation of oesophageal chest pain. Aliment Pharmacol Ther 2012;35:1474-1481.

68. Nasr I, Attaluri A, Hashmi S, Gregersen H, Rao SS. Investigation of esophageal sensation and biomechanical properties in functional chest pain. Neurogastroenterol Motil 2010;22:520-526, e116.

69. Drewes AM, Schipper KP, Dimcevski G, et al. Multi-modal induction and assessment of allodynia and hyperalgesia in the human oesophagus. Eur J Pain 2003; 7:539-549.

70. Farmer AD, Coen SJ, Kano M, et al. Psychological traits influence autonomic nervous system recovery following esophageal intubation in health and functional chest pain. Neurogastroenterol Motil 2013;25:950-e772.

71. Demiryoguran NS, Karcioglu O, Topacoglu H, et al. Anxiety disorder in patients with non-specific chest pain in the emergency setting. Emerg Med J 2006;23:99-102.

72. George N, Abdallah J, Maradey-Romero C, Gerson L, Fass R. Review article: the current treatment of non-cardiac chest pain. Aliment Pharmacol Ther 2016;43:213-239.

73. Hershcovici T, Achem SR, Jha LK, Fass R. Systematic review: the treatment of noncardiac chest pain. Aliment Pharmacol Ther 2012;35:5-14.

74. Dickman R, Maradey-Romero C, Fass R. The role of pain modulators in esophageal disorders - no pain no gain. Neurogastroenterol Motil 2014;26:603-610.

75. Nguyen TM, Eslick GD. Systematic review: the treatment of noncardiac chest pain with antidepressants. Aliment Pharmacol Ther 2012;35:493-500.

76. Sperber AD, Drossman DA. Review article: the functional abdominal pain syndrome. Aliment Pharmacol Ther 2011;33:514-524

77. Drossman DA, Track J, Ford AC, Szigethy E, Törnblom H, Van Oudenhove L. Neuromodulators for functional gastrointestinal disorders (disorders of gut-brain interaction) : a Rome foundation working team report. Gastroenterology 2018;154:1140-1171, e1.

78. Cannon RO 3rd, Quyyumi AA, Mincemoyer R, et al. Imipramine in patients with chest pain despite normal coronary angiograms. N Engl J Med 1994;330:1411-1417.

79. Cox ID, Hann CM, Kaski JC. Low dose imipramine improves chest pain but not quality of life in patients with angina and normal coronary angiograms. Eur Heart J 1998;19:250-254.

80. Park SW, Lee H, Lee HJ, et al. Low-dose amitriptyline combined with proton pump inhibitor for functional chest pain. World J Gastroenterol 2013;19:4958-4965.

81. Maradey-Romero C, Fass R. New therapies for non-cardiac chest pain. Curr Gastroenterol Rep 2014;16:390.

82. Sindrup SH, Otto M, Finnerup NB, Jensen TS. Antidepressants in the treatment of neuropathic pain. Basic Clin Pharmacol Toxicol 2005;96:399-409.

83. Doraiswamy PM, Varia I, Hellegers C, et al. A randomized controlled trial of paroxetine for noncardiac chest pain. Psychopharmacol Bull 2006;39:15-24

84. Spinhoven P, Van der Does AJ, Van Dijk E, Van Rood YR. Heart- 
focused anxiety as a mediating variable in the treatment of noncardiac chest pain by cognitive-behavioral therapy and paroxetine. J Psychosom Res 2010;69:227-235.

85. Varia I, Logue E, O'connor C, et al. Randomized trial of sertraline in patients with unexplained chest pain of noncardiac origin. Am Heart J 2000;140:367-372.

86. Keefe FJ, Shelby RA, Somers TJ, et al. Effects of coping skills training and sertraline in patients with non-cardiac chest pain: a randomized controlled study. Pain 2011;152:730-741.

87. Atluri DK, Chandar AK, Fass R, Falck-Ytter Y. Systematic review with meta-analysis: selective serotonin reuptake inhibitors for noncardiac chest pain. Aliment Pharmacol Ther 2015;41:167-176.

88. Gutierrez MA, Stimmel GL, Aiso JY. Venlafaxine: a 2003 update. Clin Ther 2003;25:2138-2154.

89. Harvey AT, Rudolph RL, Preskorn SH. Evidence of the dual mechanisms of action of venlafaxine. Arch Gen Psychiatry 2000;57:503-509.

90. Lee H, Kim JH, Min BH, et al. Efficacy of venlafaxine for symptomatic relief in young adult patients with functional chest pain: a randomized, double-blind, placebo-controlled, crossover trial. Am J Gastroenterol 2010;105:1504-1512.

91. Handa M, Mine K, Yamamoto H, et al. Antidepressant treatment of patients with diffuse esophageal spasm: a psychosomatic approach. J Clin Gastroenterol 1999;28:228-232.

92. Clouse RE, Lustman PJ, Eckert TC, Ferney DM, Griffith LS. Lowdose trazodone for symptomatic patients with esophageal contraction abnormalities. A double-blind, placebo-controlled trial. Gastroenterology 1987;92:1027-1036.

93. Tack J, Sarnelli G. Serotonergic modulation of visceral sensation: upper gastrointestinal tract. Gut 2002;51(suppl 1):i77-i80.

94. Rao SS, Mudipalli RS, Mujica V, Utech CL, Zhao X, Conklin JL. An open-label trial of theophylline for functional chest pain. Dig Dis Sci 2002;47:2763-2768.

95. Rao SS, Mudipalli RS, Remes-Troche JM, Utech CL, Zimmerman B. Theophylline improves esophageal chest pain--a randomized, placebocontrolled study. Am J Gastroenterol 2007;102:930-938.

96. Jaggar SI, Hasnie FS, Sellaturay S, Rice AS. The anti-hyperalgesic actions of the cannabinoid anandamide and the putative $\mathrm{CB} 2$ receptor agonist almitoylethanolamide in visceral and somatic inflammatory pain. Pain 1998;76:189-199

97. Malik Z, Bayman L, Valestin J, Rizvi-Toner A, Hashmi S, Schey R Dronabinol increases pain threshold in patients with functional chest pain: a pilot double-blind placebo-controlled trial. Dis Esophagus 2017;30:1-8.

98. Gasiorowska A, Navarro-Rodriguez T, Dickman R, et al. Clinical trial: the effect of Johrei on symptoms of patients with functional chest pain. Aliment Pharmacol Ther 2009;29:126-134.

99. Klimes I, Mayou RA, Pearce MJ, Coles L, Fagg JR. Psychological treatment for atypical non-cardiac chest pain: a controlled evaluation. Psychol Med 1990;20:605-611.

100. van Peski-Oosterbaan AS, Spinhoven P, van Rood Y, van der Does JW, Bruschke AV, Rooijmans HG. Cognitive-behavioral therapy for noncardiac chest pain: a randomized trial. Am J Med 1999;106:424-429.

101. Sanders D, Bass C, Mayou RA, Goodwin S, Bryant BM, Tyndel S. Non-cardiac chest pain: why was a brief intervention apparently ineffective? Psychol Med 1997;27:1033-1040

102. Jonsbu E, Dammen T, Morken G, Moum T, Martinsen EW. Shortterm cognitive behavioral therapy for non-cardiac chest pain and benign palpitations: a randomized controlled trial. J Psychosom Res 2011;70:117-123.

103. Jonsbu E, Martinsen EW, Morken G, Moum T, Dammen T. Change and impact of illness perceptions among patients with non-cardiac chest pain or benign palpitations following three sessions of CBT. Behav Cogn Psychother 2013;41:398-407.

104. Cott A, McCully J, Goldberg WM, Tanser PH, Parkinson W. Interdisciplinary treatment of morbidity in benign chest pain. Angiology 1992;43(3 Pt 1):195-202.

105. Jones H, Cooper P, Miller V, Brooks N, Whorwell PJ. Treatment of non-cardiac chest pain: a controlled trial of hypnotherapy. Gut 2006;55:1403-1408.

106. Potts SG, Lewin R, Fox KA, Johnstone EC. Group psychological treatment for chest pain with normal coronary arteries. QJM 1999;92:81-86. 